\title{
Editorial
}

\section{Utilization of "Screening Brief Intervention and Referral to Treatment" Approach for Tobacco Addiction in Day-to-Day Clinical Practice in India: The Need of the Hour}

India is home to second highest number of tobacco users in the world after China regarding numbers as well as proportion, which contribute to high morbidity and mortality rates. According to "Global Adult Tobacco Survey 2," 28.6\% (266.8 million) of adult Indians use tobacco in some form. ${ }^{[1]}$ The Government of India through its decade-old "National Tobacco Control Program" addresses the issue of tobacco use by increasing awareness about harmful effects of tobacco and more stringent tobacco control laws. Suggested interventions for decreasing tobacco use include school/ community-based and adult education interventions, and cessation assistance, facilitated by trained health professionals and schoolteachers. ${ }^{[2]}$ In this regard, it is important for all clinicians/health workers concerned with providing clinical services to the patients suffering from direct or indirect adverse health effects due to tobacco dependence to get familiar with various screening and cessation strategies for tobacco use. The first contact of help-seeking in patients suffering from tobacco addiction may range from pulmonologist, cardiologist, oncologist, or any other specialist. It is noteworthy to know that the prevalence of tobacco addiction/problem is quite high in patients approaching these specialists. The same is evident in the study "Pattern of psychiatric morbidity in chronic obstructive pulmonary disease (COPD) patients in Kashmir" in this issue of Journal of Neurosciences in Rural Practice where $74 \%$ of patients with COPD had a history of smoking. ${ }^{[3]}$ There is considerable scope for screening and treatment of tobacco addiction in such settings. A simple screening and advice using systematic approach such as Screening Brief Intervention and Referral to Treatment (SBIRT) can make a huge difference and could prove an effective public health strategy for tobacco control in India.

SBIRT is a universal, comprehensive, integrated, evidence-based, and public health approach for early intervention, and treatment of substance uses disorders including tobacco use disorder. ${ }^{[4]}$ Any specialist, general practitioners, community health workers, and paramedical workers can deliver it. It is simple, brief, and can be integrated in day-to-day clinical practice. The components of SBIRT include Universal Screening (S) for identifying the unhealthy use of tobacco by asking simple questions regarding tobacco use and readiness to quit or using a specific screening tool The Alcohol,
Smoking, and Substance Involvement Screening Test Assist (A), i.e. It takes about 1-3 min for screening. For those who screen positive, further assessment is needed to determine the level of risks. The Fagerstrom test for nicotine dependence assesses the severity of dependence for both smoking and smokeless tobacco use. The brief intervention provides feedback about unhealthy tobacco use, focuses on education, increasing patient insight and awareness, and enhances motivation toward healthy behavioral change. Brief intervention can be delivered in 5-20 min with minimum training. Apart from the substance use disorders, it is useful in the treatment of various psychiatric disorders such as depression and anxiety disorder. ${ }^{[5]}$ Brief intervention can be delivered using "FRAMES" or "5 A's" model. The "FRAMES" model constitutes five components Feedback (F), i.e., providing feedback about unhealthy use of tobacco; Responsibility (R), i.e., asking patient to take responsibility for tobacco use; Advice (A), i.e., clear, firm advice regarding need to quit tobacco use; Menu of options (M), i. e. discussing about various treatment options and setting contract for tobacco cessation; Empathy (E), i.e., empathizing with patients regarding difficulties faced; and Self-efficacy (S), i.e., improving self-efficacy that is reminding patient of his/her ability to succeed in given situation. Another approach for brief intervention is "5 A's" model which also constitutes five components Ask (A), i.e., asking patient about tobacco use; Advise (A), i.e., advising importance of quitting; Assess (A), i. e. assessing willingness to quit; ASSIST (A), i.e., prescribing medications and referral; and Arrange (A), i.e., arranging follow-up for reinforcement and troubleshooting. Referral to treatment helps facilitate access to addiction assessment and treatment. A referral is usually indicated for only about $5 \%$ of people screened. The pharmacological treatment of tobacco addiction includes nicotine replacement therapy (NRT), bupropion, varenicline, nortriptyline, and clonidine. NRT in the form of nicotine gums, patches, and lozenges are widely available as over-the-counter medications in India.

Despite the effectiveness of screening and tobacco cessation in diverse healthcare setting, screening is not being practiced in day-to-day clinical practice in India for large number of patients. Less than $30 \%$ of patients visiting primary healthcare centers are screened for tobacco use, and thus opportunity for SBIRT is lost. ${ }^{[6,7]}$ 
The coverage of tobacco-cessation treatment and its integration in general healthcare system is minimal, and there are many challenges. ${ }^{[8]}$ Coordinated efforts are required from clinicians/healthcare workers to counter the tobacco problem in India.

\section{Roshan Bhad}

Department of Psychiatry, National Drug Dependence Treatment Centre, All India Institute of Medical Sciences, New Delhi, India

Address for correspondence: Dr. Roshan Bhad, Assistant Professor,

R. No. 4096, Department of Psychiatry, National Drug Dependence Treatment Centre, $4^{\text {th }}$ Floor, Academic Block, AIIMS,

Ansari Nagar, New Delhi - 110 029, India. E-mail: drroshansindia@gmail.com

\section{REFERENCES}

1. Global Adult Tobacco Survey 2 India 2016-17 Report. Ministry of Health and Family Welfare, Government of India. Available from: https://www.mohfw.gov.in/newshighlights/ global-adult-tobacco-survey-2-gats-2-india-2016-17-report. [Last accessed on 2018 Aug 14].

2. McKay AJ, Patel RK, Majeed A. Strategies for tobacco control in India: A systematic review. PLoS One 2015;10:e0122610.

3. Dar SA, Bhat BA, Shah NN, Imtiyaz SB. The pattern of psychiatric morbidity in chronic obstructive pulmonary disease: A cross-sectional, case control study from a tertiary care hospital in Kashmir, North India. J Neurosci Rural Pract 2018;10:65-70.

4. Babor TF, McRee BG, Kassebaum PA, Grimaldi PL, Ahmed K, Bray $\mathrm{J}$, et al. Screening, brief intervention, and referral to treatment (SBIRT): Toward a public health approach to the management of substance abuse. Subst Abus 2007;28:7-30.
5. Bhad R. The role of brief intervention in psychiatry. Indian $\mathrm{J}$ Psychosoc Sci 2014;2:15-7.

6. Mullen KA, Manuel DG, Hawken SJ, Pipe AL, Coyle D, Hobler LA, et al. Effectiveness of a hospital-initiated smoking cessation programme: 2-year health and healthcare outcomes. Tob Control 2017;26:293-9.

7. Panda R, Persai D, Venkatesan S. Missed opportunities for brief intervention in tobacco control in primary care: Patients' perspectives from primary health care settings in India. BMC Health Serv Res 2015;15:50.

8. Varghese C, Kaur J, Desai NG, Murthy P, Malhotra S, Subbakrishna DK, et al. Initiating tobacco cessation services in India: Challenges and opportunities. WHO South East Asia J Public Health 2012;1:159-68.

This is an open access journal, and articles are distributed under the terms of the Creative Commons Attribution-NonCommercial-ShareAlike 4.0 License, which allows others to remix, tweak, and build upon the work non-commercially, as long as appropriate credit is given and the new creations are licensed under the identical terms.

\begin{tabular}{|c|c|}
\hline \multicolumn{2}{|c|}{ Access this article online } \\
\hline $\begin{array}{l}\text { Quick Response Code: } \\
\text { (a) }\end{array}$ & $\begin{array}{l}\text { Website: } \\
\text { www.ruralneuropractice.com }\end{array}$ \\
\hline (5) & $\begin{array}{l}\text { DOI: } \\
\text { 10.4103/jnrp.jnrp_271_18 }\end{array}$ \\
\hline
\end{tabular}

How to cite this article: Bhad R. Utilization of "screening brief intervention and referral to treatment" approach for tobacco addiction in day-to-day clinical practice in India: The need of the hour. J Neurosci Rural Pract 2019;10:8-9. 